\title{
Independence of women through sewing skills
}

\author{
Magdalena Linda Leonita Sibarani ${ }^{1 *}$, Elita Dewi ${ }^{1}$ \\ ${ }^{1}$ Faculty of economic and business management Universitas Sumatera Utara, \\ 2 faculty of Social Science and Political Science, State Administration Science, Universitas \\ SumateraUtara \\ *Email: magdalenaleonita@gmail.com
}

\begin{abstract}
Facing an era of increasingly fierce competition, a person is required to have a high entrepreneurial spirit so that he can run a business that he lives well. Thus we must be able to see market opportunities and desires in terms of needs and selling points that we will offer to consumers.

Entrepreneurs in sewing services are still promising. Even though now there are a lot of apparel production, stitching services are still needed by consumers. Because there are some risks in purchasing apparel that are usually accepted by buyers. Not all clothes fit to be worn by consumers. Especially for people who have different body postures from the standards of people in general, such as too small or too fat. Besides that, there are certain clothes models and materials that are more comfortable when used from ordinary stitches, rather than in the form of apparel manufactured by the factory. For example, traditional clothing, brocade fabrics, suits, kebaya, woven fabrics and others.

In connection with this, it is felt necessary to provide training to improve the skills of clothing tailors to be able to produce clothes that are in accordance with market desires efficiently and effectively. Besides improving skills in spraying and embroidering in order to have the ability to compete in terms of quality, models, variations in motifs and the color combination of clothing produced, so as to create and have a lot of marketing networks. The need for training that enables tailor clothing to calculate total sales revenue and total costs so that they are able to know how much profit is obtained per piece of clothing.

It is hoped that after the mentoring, the partners will be more knowledgeable, able to apply this knowledge in their daily work and transmit this knowledge to other dressmakers. Thus, all dressmakers will develop more, become more economically independent, increase in income, tailor clothes become more productive and be more optimistic in entrepreneurship.Write abstracts in English only if the contents are in English or English and Indonesian also fill in Indonesian with a maximum of 200 words. The contents of the background abstract, the method of resolution, the results of the community service/research, discussion of the results achieved and plans for future achievements. TNR typewriting with a size of 10 .
\end{abstract}

Keyword: Tailor clothing, Increased income

Abstrak
Menghadapi era persaingan yang semakin ketat, seseorang dituntut untuk memiliki semangat
kewirausahaan yang tinggi sehingga dapat menjalankan usaha yang dijalaninya dengan baik. Dengan demikian
kita harus dapat melihat peluang-peluang dan keinginan pasar dilihat dari segi kebutuhan serta nilai jual yang
akan kita tawarkan kepada konsumen.
Wirausaha jasa menjahit pakaian masih menjanjikan. Meski sekarang sudah banyak produksi pakaian
jadi, tetapi jasa jahitan tetap dibutuhkan konsumen. Karena ada beberapa risiko pembelian pakaian jadi yang
biasanya diterima oleh pembeli. Tidak semua pakaian jadi pas dikenakan oleh konsumen. Terutama bagi orang-
orang memiliki postur tubuh berbeda dengan standar orang pada umumnya, seperti terlalu kecil atau terlalu
gemuk. Disamping itu ada model dan bahan baju tertentu yang lebih enak kalau dipakai dari hasil jahitan biasa,
daripada dalam bentuk pakaian jadi yang diproduksi pabrik. Misalnya pakaian adat, bahan brukat, jas, kebaya,
kain tenun dan lain-lain.
Sehubungan dengan hal tersebut, maka dirasa perlu diberikan pelatihan peningkatan ketrampilan
kepada penjahit pakaian agar mampu menghasilkan pakaian yang sesuai dengan keinginan pasar secara efisien
dan efektif. Selain itu meningkatkan ketrampilan dalam mengobras dan membordir agar memiliki kemampuan
bersaing dari sisi kualitas, model, variasi motif dan perpaduan warna pakaian yang di produksi, sehingga 
mampu menciptakan dan memiliki banyak jaringan pemasaran. Perlunya diberikan pelatihan yang memampukan penjahit pakaian menghitung total pendapatan penjualan dan total biaya sehingga mampu mengetahui berapa laba yang diperoleh per satu potong pakaian.

Diharapkan setelah pendampingan, para mitra menjadi lebih meningkat pengetahuannya, mampu mengaplikasikan pengetahuan tersebut dalam pekerjaan sehari-harinya dan menularkan pengetahuan tersebut kepada pelaku wirausaha penjahit pakaian yang lain. Dengan demikian semua penjahit pakaian akan lebih berkembang, menjadi semakin mandiri secara ekonomis, terjadi peningkatan pendapatan, penjahit pakaian menjadi lebih produktif serta semakin optimis dalam berwirausaha.

\section{Kata kunci: Penjahit pakaian, Peningkatan Pendapatan}

\section{PENDAhUluan}

Menjadi wirausaha berarti memiliki kemampuan menemukan dan mengevaluasi peluangpeluang, mengumpulkan sumber-sumber daya yang diperlukan dan bertindak untuk memperoleh keuntungan-keuntungan dari peluang-peluang itu. Wirausaha harus meluangkan sebagian besar waktunya untuk merencanakan kegiatan-kegiatan bisnis. Dengan bertumbuhnya perusahaan, kebutuhan akan perencanaan semakin besar. Waktu tak dapat ditabung, waktu harus digunakan secara bijaksana. Para wirausaha perlu mengelola waktunya dengan efektif, dan kunci penggunaan waktu yang terletak dalam manajemen yang lebih baik. Berangkat dari hal-hal tersebut maka seorang wirausaha dituntut untuk bisa memanage atau mengendalikan pribadi sikapnya secara benar.

Sikap mental yang tepat terhadap pekerjaan sangatlah penting. Para wirausaha yang berhasil menikmati pekerjaan mereka dan berdedikasi total terhadap apa yang mereka lakukan. Sikap mental positif mereka mengubah pekerjaan mereka menjadi pekerjaan yang menggairahkan, menarik dan memberi kepuasan.

Menghadapi era persaingan yang semakin ketat, seseorang dituntut untuk memiliki semangat kewirausahaan yang tinggi sehingga dapat menjalankan usaha yang dijalaninya dengan baik. Dengan demikian kita harus dapat melihat peluang-peluang dan keinginan pasar dilihat dari segi kebutuhan serta nilai jual yang akan kita tawarkan kepada konsumen. Dalam menjalankan suatu usaha (wirausaha) seorang pelaku usaha harus memiliki :

\section{Skill (kemampuan)}

Seorang pelaku usaha harus memiliki skil (kemampuan) untuk berwirausaha karna tanpa skil (kemampuan) seorang pelaku usaha tidak akan mungkin bisa berwirausaha. Jadi skill (kemampuan) adalah modal utama yang harus dimiliki dalam berwirausaha.

2. Tekad (kemauan)

Apabila seorang pelaku usaha telah mempunyai skill (kemampuan) tapi tanpa ada tekad (kemauan yang kuat) untuk berwirausaha maka skill (kemampuan) berwirausaha itu akan sia-sia karena tidak dapat tersalurkan. Jadi pada dasarnya skill dan tekad itu harus dimiliki oleh seorang pelaku wirausaha

3. Modal

Modal merupakan aspek yang sangat menunjag dalam hal memulai dan menjalankan suatu usaha disamping mempunyai skill dan tekad.

4. Target dan Tujuan

Seorang pelaku usaha apabila ingin menjalankan suatu usaha maka harus bisa menentukan targer dan tujuan pemasarannya. Karena apabila target dan tujuan tidak direncanakan maka usaha yang dijalankan tidak mungkin dapat bertahan lama.

5. Tempat

Tempat berwirausaha merupakan aspek yang harus dimiliki bila ingin menjalankan wirausaha. Karena tempat juga sangat menunjang dalam hal wirausaha dan bisa menjadikan suatu bahan pertimbangan oleh konsumen mengenai wirausaha yang sedang dijalankan. 
Dewasa ini, menjalankan wirausaha jasa menjahit pakaian masih menjanjikan. Meski sekarang sudah banyak produksi pakaian jadi, tetapi jasa jahitan tetap dibutuhkan konsumen. Karena ada beberapa risiko pembelian baju jadi yang biasanya diterima oleh pembeli.

Pakaian jadi biasanya dibuat dengan ukuran standar (S, M, L, dan XL). Meski model dan bahannya cukup bervariasi dan harganya pun lebih murah dibandingkan memakai jasa penjahit, tetapi tidak semua pakaian jadi pas dikenakan oleh konsumen. Terutama bagi orang-orang memiliki postur tubuh berbeda dengan standar orang pada umumnya, seperti terlalu kecil atau terlalu gemuk. Jasa jahitan akan tetap diburu oleh orang seperti ini.

Di samping itu ada model dan bahan baju tertentu yang lebih enak kalau dipakai dari hasil jahitan biasa, daripada dalam bentuk pakaian jadi yang diproduksi pabrik. Misalnya pakaian adat, bahan brukat, jas, kebaya, kain tenun dan lain-lain.

Mitra pengabdian adalah kaum perempuan di Desa Tanjung Anom Kecamatan Pancur Batu Kabupaten Deli Serdang yang membuka usaha jasa menjahit pakaian. Mitra sebenarnya mengkhususkan jasa menjahit pakaian kebaya, tetapi ada kalanya menerima jahitan pakaian lainnya seperti rok, baju, celana dan pakaian lainnya. Mereka masih memiliki alat yang terbatas, hanya mesin jahit. Untuk mengobras dan membordir masih harus mengantarkannya ke Pancur Batu atau ke Pringgan, sehingga membutuhkan waktu produksi yang lebih lama. Hal ini menjadikan mereka kurang efisien dalam pengerjaannya. Disamping itu kesempatan untuk memperoleh untung yang lebih besar menjadi hilang.

Sehubungan dengan analisis situasi di atas, maka tim pengusul merasa tertarik untuk melakukan pengabdian pada masyarakat yang diberi judul "Kemandirian Perempuan Melalui Keterampilan Menjahit”.

\section{Permasalahan Mitra}

a. Rendahnya kapasitas perempuan penjahit pakaian dalam memahami persoalan-persoalan yang mereka hadapi.

b. Rendahnya keterampilan mitra dalam menjahit pakaian sehingga kurang mampu bersaing dari sisi kualitas, model, variasi motif dan perpaduan warna.

c. Minimnya peralatan yang dimiliki mitra membuat hilangnya kesempatan memperoleh pendapatan yang lebih tinggi.

d. Rendahnya pengetahuan perempuan penjahit pakaian dalam memproduksi secara efektif dan efisien melalui perhitungan laba dan analisis biaya yang lebih baik, sehingga mampu meningkatkan pendapatan perempuan penjahit pakaian.

\section{SOLUSI DAN TARGET LUARAN}

\section{Solusi yang Ditawarkan}

Untuk meningkatkan daya saing wiausaha jasa menjahit pakaian, maka dirasa perlu melakukan pengabdian kepada perempuan penjahit pakaian dengan cara :

1. Ceramah dan diskusi, untuk mengetahui lebih jelas permasalahan dasar penjahit pakaian, sehingga bisa diberikan solusi masalah.

2. Mengadakan sosialisasi arti penting wirausaha jasa menjahit pakaian. Membuat perempuan di Desa Tanjung Anom menjadi mandiri secara ekonomis. Meyakinkan mereka bahwa usaha jasa menjahit pakaian tetap akan diminati bila diproduksi sesuai dengan selera pasar dan dengan proses produksi yang efektif dan efisien.

3. Melaksanakan pelatihan dengan mengundang pakar obras dan bordir agar memiliki kemampuan memproduksi pakaian atau menjahit pakaian yang berkualitas baik dalam model, variasi motif dan juga perpaduan warna. Pemberian mesin pendukung diyakini membuat pelatihan akan lebih berhasil.

4. Melatih penjahit pakaian agar mampu memproduksi secara efektif dan efisien melalui perhitungan laba dan analisis biaya yang lebih baik, sehingga mampu meningkatkan pendapatan perempuan penjahit pakaian. 


\section{Target luaran}

Luaran yang dihasilkan setelah selesainya kegiatan pengabdian pada masyarakat ini adalah :

1. Meningkatnya kapasitas mitra perempuan penjahit pakaian sehingga mampu memahami persoalan-persoalan yang mereka hadapi.

2. Meningkatnya pengetahuan dan keterampilan perempuan penjahit pakaian dalam mengobras dan membordir juga mampu menembus pasar yang lebih luas.

3. Meningkatnya keterampilan mitra dalam memproduksi pakaian sehingga mampu bersaing dari sisi kualitas, model, variasi motif dan perpaduan warna.

4. Menambah kemampuan dan skill para penjahit pakaian dalam menghitung total pendapatan, mengetahui faktor-faktor yang menentukan besarnya pendapatan penjualan. Mampu menghitung total biaya dan mengetahui cara untuk meminimalkan biaya produksi serta memampukan penjahit pakaian menghitung keuntungan per satu potong pakaian dan total keuntungan per bulan.

\section{METODE PELAKSANAAN}

\subsection{Metode Pendekatan}

Metode pendekatan yang dilakukan selama melakukan pengabdian kepada mitra adalah dengan cara melakukan ceramah, sosialisasi, pelatihan, bimbingan dan pendampingan terhadap penjahit pakaian yang menjadi mitra. Pengukuran perubahan terhadap perilaku mitra dapat dilihat dari perilaku mitra yang berubah menjadi terbiasa dan mampu menghasilkan pakaian dengan cara yang efisien dan dengan kualitas yang bagus, dan motif yang sesuai dengan selera pasar, tetapi tetap berpegang pada budaya.

Mitra menjadi mengetahui teknik melakukan kegiatan produksi yang efektif dan efisien. Melalui kegiatan pengabdian ini mitra juga diharapkan semakin memiliki mental kewirausahaan serta mampu meningkatkan penjualannya dan jaringannya setelah diberikan pelatihan.

\subsection{Rencana Kegiatan}

Rencana kegiatan yang akan dilakukan untuk pemecahan masalah adalah dengan tahapan sebagai berikut :

1. Sosialisasi

Sosialisasi dilakukan kepada perempuan penjahit pakaian di Desa Tanjung Anom

Kabupaten Deli Serdang. Materi sosialisasi adalah makna wirausaha jasa menjahit pakaian dapat meningkatkan pendapatan dan kesejahteraan masyarakat Tanjung Anom.

2. Ceramah dan diskusi

Setelah kegiatan sosialisasi dilakukan tim pengabdian akan melakukan ceramah dan diskusi tentang rencana kegiatan. Berdasarkan ceramah dan diskusi ini tim pengabdian akan dapat mengetahui ketertarikan masyarakat terhadap kegiatan pengabdian. Selain itu dapat membangun motivasi tinggi untuk meningkatkan keterampilan.

3. Rekrutmen

Rekrutmen adalah bentuk pernyataan selain mitra yang bersedia untuk mengikuti kegiatan pengabdian. Penjahit pakaian yang bersedia selanjutnya dibimbing untuk mengikuti jadwal kegiatan pengabdian. Kegiatan rekrutmen ini bersifat sukarela tanpa ada paksaan ataupun tekanan dari siapapun.

4. Pelatihan Menjahit, Mengobras dan Membordir

Pelatihan dilakukan dengan mengundang orang yang memang sudah diakui keahliannya. Dalam pelatihan ini maka tim pengabdian akan memfasillitasi dan menyediakan semua bahan-bahan dan peralatan yang diperlukan dalam pembuatan pakaian tersebut. Pelatihan 
ini diharapkan akan meningkatkan keterampilan para mitra sehingga hampir sama dengan keterampilan tutornya.

5. Evaluasi

Evaluasi akan dilakukan selama pelaksanaan kegiatan pengabdian di Tanjung Anom yang meliputi pengamatan keterampilan dalam menjahit, mengobras dan membordir pakaian. Selain itu juga evaluasi akan dilakukan meskipun kegiatan pelatihan sudah selesai, yaitu dengan bertelepon menanyakan kemajuan wirausaha jasa menjahit pakaian juga dengan mengunjungi kembali mitra menanyakan keuntungan dan hambatan yang dijumpai setelah kegiatan pelatihan selesai dilakukan.

\subsection{Kontribusi Partisipasi Mitra}

Dalam pelaksanaan pengabdian ini mitra pengabdian diharapkan memberikan kontribusi sebagai berikut :

1. Mitra bersedia mengikuti segala bentuk pelatihan dan berniat untuk merubah cara kerja menjadi lebih efisien dan efektif.

2. Mitra bersedia juga mengikuti pelatihan para penjahit pakaian dalam menghitung total pendapatan, mengetahui faktor-faktor yang menentukan besarnya pendapatan penjualan.

Mitra mampu menghitung total biaya dan mengetahui cara untuk meminimalkan biaya produksi serta mampu menghitung keuntungan per satu potong pakaian dan total keuntungan per bulan.

3. Mitra bersedia dan diteguhkan untuk membangun karakter wirausaha agar mengubah pola kerja, sehingga pekerjaan menjahit pakaian dapat diselesaikan tepat waktu sesuai dengan yang sudah disepakati.

\section{HASIL DAN PEMBAHASAN}

Meskipun survey pra pengabdian telah dilakukan akan tetapi kegiatan pengabdian dimulai kembali dengan forum grup diskusi (FGD) yang membahas permasalahan-permasalahan yang dialami oleh mitra pengabdian. Hal ini dilakukan untuk lebih mengenali dan merumuskan permasalahan yang sesungguhnya dialami oleh mitra pengabdian. Dan kegiatan FGD ini akan kerap dilakukan untuk berbagi berbagai macam informasi dan pengetahuan sekaligus mencari solusi terhadap berbagai macam permasalahan yang dihadapi oleh mitra.

Dari diskusi yang telah dilakukan berbagai permasalahan mitra pengabdian dapat diidentifikasi sebagai berikut : meningkatkan pengetahuan mitra mengenai masalah manajemen usaha, perhitungan harga pokok produksi dan pelatihan peningkatan ketrampilan. Permasalahan-permasalahan tersebutlah yang diyakini telah membuat operasional usaha mitra berjalan kurang efektif.

Kegiatan penyuluhan disepakati dilaksanakan di lokasi mitra. Metode penyuluhan dilakukan dengan metode ceramah kepada semua anggota kelompok mitra yang dilakukan secara berkelompok. Selanjutnya dilakukan pemberian hibah bantuan berupa mesin-mesin penunjang usaha mitra, serta bahan dan peralatan penunjang lainnya.

Ketrampilan menjahit pakaian nampaknya sudah menunjukkan kemajuan yang baik namun sembari itu harus terus berlatih, karena hasilnya kelihatannya sudah cukup rapi. Namun demikian mitra abdi sudah berani menerima orderan menjahit pakaian dan melaksanakannya dengan penuh tanggung jawab. Hal ini sangatlah membanggakan karena mitra menunjukkan jiwa wirausahawan yang berani mengambil resiko sembari terus belajar dan berlatih.

Dengan peningkatan produksi dan produktivitas mitra abdi maka meningkat pulalah penghasilannya. Namun demikian mitra harus lebih disiplin dalam melakukan pencatatan pembukuannya. Karena terkadang masih dijumpai adanya biaya yang tidak atau lupa dicatatkan oleh 
mitra abdi. Sehingga perhitungan rugi laba dari usaha jasa menjahit yang dijalankan kurang atau tidak benar.

Kemampuan untuk mengetahui dan mendapatkan model-model terbaru kelihatannya sudah sangat dipahami oleh mitra abdi. Sehingga mitra pengabdian akan sudah dapat menjahit pakaian dengan model-model terbaru atau up to date sesuai dengan selera konsumen.

\section{KESIMPULAN}

Kesimpulan

1. Tumbuhnya minat mitra pengabdian menjadi pelaku wirausaha menjahit.

2. Ketrampilan dan pengetahuan mitra pengabdian meningkat

3. Mitra pengabdian telah mampu menyusun pembukuan sederhana wirausaha menjahitnya.

4. Mitra pengabdian telah mampu mengembangkan wirausahanya.

5. Terjadi peningkatan pendapatan wirausaha mitra pengabdian.

\section{UCAPAN TERIMAKASIH}

Terselenggaranya kegiatan pengabdian masyarakat ini serta penulisan jurnal pengabdian masyarakat ini tidak dapat dipisahkan dari dukungan pendanaan Non PNBP Universitas Sumatera Utara. Untuk itu Tim pengabdian pada masyarakat mengucapkan terima kasih kepada Rektor Universitas Sumatera Utara serta Ketua dan Sekretaris serta staf Lembaga Pengabdian Kepada Masyarakat Universitas Sumatera Utara. Ucapan terima kasih juga ditujukan kepada pihak LPPM USU yang telah memberikan dana kepada pengabdian ini. Terima kasih juga kepada pihak mitra yang telah koopratif di dalam pelaksanaan pengabdian ini.

\section{DAFTAR PUSTAKA}

Alma, B. (2008). Manajemen Pemasaran dan Pemasaran Jasa. Bandung : Penerbit Alfabeta

Brigham, Eugene F., \& Joel, F. H. (2004). Fundamentals of Financial Management, 10e. International Student Edition. Thomson Learning

Cravens, \& David, W. (2009). Strategic Marketing. Seventh Edition. Boston: Irwin McGraw-Hill

Ferdinand, A. (2002). Marketing Strategy Making: Proses dan Agenda Penelitian. Journal Sains Pemasaran Indonesia. Vol 1, No.1, Mei, p.1-22

Hisrich \& Peters. (2002). Entrepreneurship, Fifth Edition. New York: McGraw-Hill Higher Education

Kotler, Phillip. (2008). Marketing Management - The Millenium Edition. Prentice Hall

Salvatore, Dominick. (2005). Managerial Economics. Edisi Kelima. Jilid Kedua. Jakarta : Salemba Empat.

Suryana. (2006). Kewirausahaan Pedoman Praktis : Kiat dan Proses Menuju Sukses. Jakarta:Salemba Empat

Sutojo, Siswanto. (2003). Manajemen Penjualan yang Efektif. PT. Darma Mulia Pustaka 